\title{
Abortion Trauma in the Context of Chinese Culture
}

\author{
Wan Zaojun, Yuan Yuan* \\ School of Sociology and Psychology, Central University of Finance and Economics, Beijing, China
}

Email address:

18813080328@sina.cn (Yuan Yuan)

${ }^{*}$ Corresponding author

\section{To cite this article:}

Wan Zaojun, Yuan Yuan. Abortion Trauma in the Context of Chinese Culture. Psychology and Behavioral Sciences. Vol. 8, No. 5, 2019, pp. 138-141. doi: 10.11648/j.pbs.20190805.16

Received: September 8, 2019; Accepted: October 7, 2019; Published: October 23, 2019

\begin{abstract}
Abortion in the family has a profound and traumatic impact on individual psychological state. In China, the number of abortion operations remains high, which has attracted the attention and research of many scholars. However, there is a lack of discussion on the trauma of abortion in these studies. Abortion trauma is not only affected by individual psychological factors, but also by social and cultural factors. In order to analyze the characteristics of abortion trauma under the background of Chinese culture, explore the correlation between abortion trauma and sacrifice prototype, and strengthen the clinical intervention research on abortion trauma, this paper analyzed the questionnaire survey (296 valid questionnaires) conducted by 306 subjects. The results showed that: (1) under the background of Chinese culture, abortion trauma can occur in both an abortionist and her partner (including spouse). In a family with an abortion, the offspring will have abortion trauma; (2) the concept of sacrifice appears in the cognition of the abortionists and of the offspring of the abortionists' families. In future researches, the relationship between abortion trauma and sacrificial archetype under the background of Chinese culture can be discussed in depth, so as to explore the narrative script of abortion trauma in the collective unconscious of contemporary Chinese people, so that psychologists can better create a set of psychological intervention methods to help people get rid of abortion trauma.
\end{abstract}

Keywords: Abortion Trauma, Sacrifice Archetype, Psychological Interventions

\section{Introduction}

In recent years, in the field of clinical psychology, more and more psychological counselors are finding that abortion, as a source of trauma, has a long-term traumatic impact on a woman's mental health [1, 2-4]. A study of post-abortion syndrome found that abortion has the following consequences for women: $23 \%$ had hallucinations related to the abortion; $35 \%$ perceived visitation from the aborted child; $54 \%$ had nightmares related to the abortion; $69 \%$ experienced feelings of "craziness"; 73\% had flashbacks of abortion experience; $81 \%$ had a preoccupation with the aborted child. The most common behavioral problems in women after abortion are: $61 \%$ increased their use of alcohol; $65 \%$ had suicide ideation; $69 \%$ were sexually inhibited; $73 \%$ had flashbacks of the abortion; $77 \%$ experienced an inability to communicate; $81 \%$ experienced frequent crying [5]. At the same time, some psychological counselors find that some clients still suffer psychic trauma due to the abortion of their senior family members even if they have not experienced an abortion themselves [6]. In a study of "the sacrifice of fetuses and infants" conducted by Chinese psychologists Zhu Jianjun, Cao $\mathrm{Yu}$ and Yuan Yuan, it is found that those involved also suffered from psychic trauma [6].

The number of abortions in China remains high. On the one hand, because China implemented the national family planning policy from 1982 to 2016, the total number of birth control operations in 1982 increased by $48 \%$ compared with that in 1981, and the number of birth control operations in 1983 increased by $73 \%$ compared with that in 1982, reaching an all-time high [7]. On the other hand, with the development of social economy and culture as well as the promotion of the reform and opening up, the Chinese concept of sex has undergone a great change. According to the 2018 China Health Statistics Yearbook, there were about 9.62 million abortions in China in 2017, not much changed from previous years. (The actual number of abortions in China is much higher, since official statistics are limited to public hospitals. Marie Stopes International, an international reproductive health agency, puts the figure at 40 million, based on sales of abortion drugs in China.) The issue of abortion has aroused 
wide attention in China.

When it comes to abortion, Chinese concerns are different from those in the west: there is less discussion about the bioethics of abortion in China, because abortion is a relatively private issue in Chinese culture. Meanwhile, in rural China in the past, due to underdeveloped medical care, women often had miscarried during pregnancy.

Current research on abortion in China, influenced by western thought and self-reflection, mainly focuses on its legality and bioethics, based on Chinese cultural background. Some studies explore the reasons for the prevalence of abortion in China and try to give some methods to control the number of abortions, especially among teenagers, such as education, medicine and other fields. However, the psychological trauma caused by abortion to the clients and related persons is rarely discussed. Therefore, we used the questionnaire results of "the sacrifice of fetuses and infants" for statistics and analysis, and analyzed interview data on "abortion trauma", to explore the abortion trauma and its characteristics in the context of Chinese culture. It provides a new research direction and clinical intervention idea for abortion trauma.

The research hypotheses are as follows:

H1 (a): Abortion trauma can occur in both an abortionist and her partner (including spouse).

H1 (b): In a family with an abortion, the offspring will have abortion trauma.

$\mathrm{H} 2$ : The concept of sacrifice appears in the cognition of the abortionists and of the offspring of the abortionists' families.

\section{Methods}

\subsection{Subjects}

We issued 306 questionnaires and collected 297 valid ones (34 males and 263 females, mean age $=38.89$ years, $\mathrm{SD}=$ 8.22 ). The recovery rate was $97.1 \%$.

\subsection{Measurement}

Based on the relevant literature and our clinical practice, we compiled the abortion story questionnaire. It has 23 questions. In addition to basic information, this questionnaire examined the participants' intention, reasons, effects (for themselves and their families) of abortion, the gender of the fetus, the perception, feeling, pain of the fetus, and self-assessment of pain.

Just to be clear, the final question is: "what is the specific image and experience/emotion of apologizing to a female fetus?" The purpose of this topic is to explore the narrative script of abortion trauma in the collective unconscious of contemporary Chinese people, so as to create a set of targeted psychological intervention methods. It is not the main purpose of this study, so the relevant data are not reported here.

\section{Results}

The statistical results of the trial of abortion trauma are as follows:
Table 1. Statistics on abortion experience and abortion trauma $(n=297)$.

\begin{tabular}{lllll}
\hline & \multicolumn{2}{l}{ Abortion experience } & \multicolumn{2}{l}{ Abortion trauma } \\
\cline { 2 - 5 } & Numbers & Percentage (\%) & Numbers & Percentage (\%) \\
\hline YES & 209 & 70.4 & 241 & 81.1 \\
NO & 83 & 27.9 & 10 & 3.4 \\
NOT SURE & 4 & 1.3 & 44 & 14.8 \\
VACANCY & 1 & 0.3 & 2 & 0.7 \\
\hline
\end{tabular}

In table 1, 243 data are obtained by excluding the subjects whose answers are not sure and vacant. The details are as follows:

Table 2. Card square analysis statistics of abortionists $(n=243)$.

\begin{tabular}{llll}
\hline & & \multicolumn{2}{l}{ Abortion trauma } \\
\cline { 3 - 4 } & & NO & YES \\
\hline Abortion & NO & 5 & 66 \\
experience & YES & 2 & 170 \\
\hline
\end{tabular}

The participants rated sadness, guilt, fear, injustice and worry as quite common feelings.

Table 3. Subjects' views on the feelings of abortion $(n=306)$.

\begin{tabular}{lll}
\hline & Frequency & Percentage (\%) \\
\hline No feel & 35 & 11.44 \\
Happy & 10 & 3.27 \\
Anger & 116 & 37.91 \\
Sad & 245 & 80.07 \\
Fear & 217 & 70.92 \\
Worry & 169 & 55.23 \\
Relief & 41 & 13.40 \\
Injustice & 190 & 62.09 \\
Guilt & 235 & 76.80 \\
Shame & 146 & 47.71 \\
Others & 24 & 7.84 \\
\hline
\end{tabular}

At the same time, 259 of the participants thought the fetus was suffering physically, and 254 of the participants thought the fetus was suffering psychologically. Of the participants who felt pain in the fetus, 195 chose extreme pain, 74 chose severe pain, 11 chose moderate pain, and 8 chose mild pain.

The results of the extraction of the invalid data are analyzed: $\mathrm{x}^{2}=6.21, p=0.01<0.05$. Thus, the abortion trauma can be formed by the abortion experience of the clients and their partners.

Of the 83 people who had not had an abortion themselves or their partners, we carried out a further analysis of their family members' abortion experience and found that 61 had family members who had had an abortion, 8 had family members who had not had an abortion, and 14 did not know the specific situation. Of the 69 people who answered the question explicitly, 57 had abortion trauma and the remaining $12 \mathrm{did}$ not.

Table 4. Card square analysis statistics of offspring $(n=69)$.

\begin{tabular}{llll}
\hline & & \multicolumn{2}{l}{ Abortion trauma } \\
\cline { 3 - 4 } & & NO & YES \\
\hline Abortion & NO & 4 & 4 \\
experience & YES & 8 & 53 \\
\hline
\end{tabular}

The results of the extraction of the invalid data are analyzed: $\mathrm{x}^{2}=6.70, p=0.01<0.05$. This suggests that a family with an 
abortion experience can trigger abortion trauma in the offspring.

Confusingly, $50 \%$ of the subjects would still choose to have an abortion, even if they knew it would cause great physical and psychological harm. The reasons why the subjects chose abortion voluntarily are as follows:

Table 5. Statistical table of abortion reasons $(n=297)$.

\begin{tabular}{lll}
\hline & Frequency & Percentage (\%) \\
\hline Vacancy & 1 & 0.34 \\
Son preference & 151 & 50.84 \\
Unwed pregnant & 201 & 67.68 \\
Family planning policy & 197 & 66.33 \\
Getting pregnant at the wrong time & 186 & 62.63 \\
Not wanting children & 108 & 36.36 \\
Other reasons & 49 & 16.50 \\
\hline
\end{tabular}

\section{Discussion}

\subsection{Comprehensive Discussion}

Both research hypotheses in this study have been effectively verified.

More than half choose abortion for four reasons: pregnancy before marriage, family planning policy, getting pregnant at the wrong time and son preference. They have to bear different stresses, such as public opinion stress, policy stress, moral stress, economic stress, work stress, life stress, mental stress, gender expectations within the family, pregnant women's gender expectations and so on. People choose abortion voluntarily not because they are confident that they will not be affected by the trauma of abortion, but because they think it is easier bear the trauma than to deal with all kinds of stresses.

In other words, people are willing to give up the fetus in exchange for an easier life or identification of others. This kind of sacrifice was more common in the old society of economically underdeveloped China [8].

The questionnaire of this study deals with sacrificial offerings. Influenced by traditional Chinese culture, people tend to associate sacrificial offerings with the father of the aborted fetus, paternal family, family authority and patriarchal culture [9].

In the context of Chinese culture, post-abortion trauma is widespread, especially within families. Chinese culture tends to express implicitly, which is easy for people to suppress emotions, particularly negative ones [10]. However, psychological trauma and repressed emotions will not disappear automatically, and will affect one's life, and even change one's character.

\subsection{Limitations of Research}

(1) The sample is not balanced enough. The gender and age of subjects were not controlled. With better data, we can analyze the typical effects of abortion trauma on people of different ages and genders. In addition, no abortion practitioners were involved in this study. In fact, we think that whether the doctors and nurses who perform abortions can experience abortion trauma.

(2) The questions did not address the abortion patients' own internal experience and pain level. As a result, we will not be able to explore in depth whether or how there are differences between the abortion trauma of the abortionist and the family offspring. Obviously, it is not conducive to further research on abortion trauma intervention.

\subsection{The Prospect of Research}

First, the research results showed that the concept of sacrifice appears in the cognition of the abortionists and of the offspring of the abortionists' families. This study cannot explore the Sacrificial Archetype [11] in depth from the perspective of collective subconscious. The correlation between abortion trauma and Sacrificial Archetype [12] under the background of Chinese culture is a quite worth exploring issue, such as patriarchy culture, psychosocial trauma, collective subconscious motivation, collective subconscious needs [13], etc.

Second, explore the narrative script of abortion trauma in the collective unconscious of contemporary Chinese people, with a view to creating a set of psychological intervention methods (e.g., Sand-play, Psychodrama, Imagery Communication Psychotherapy, contemporary fairy tales, theme painting or theme dancing, etc.) [14-16]. We hope that the methods developed in the future will help people achieve a degree of transformation and healing, thus activating the seeds of healing in the collective unconscious.

\section{Conclusion}

(1) Under the background of Chinese culture, abortion trauma can occur in both an abortionist and her partner (including spouse). In a family with an abortion, the offspring will have abortion trauma;

(2) The concept of sacrifice appears in the cognition of the abortionists and of the offspring of the abortionists' families.

\section{References}

[1] Liu Bing. Mao Hong \& Wang Haiming. (2012). Investigation on 2999 cases of induced abortion in women of childbearing age. Shanghai Journal of Preventive Medicine, 24 (3): 143-144.

[2] Pu Weiqin. (2014). An analysis of the causes and coping styles of emotional disorders in women undergoing abortion. Contemporary Medicine Forum, (13): 283.

[3] Shi Chuan. Jiang Fen \& Guo Honghua. (2015). Effects of induced abortion on women's long-term mental health. Chinese Journal of Family Planning \& Gynecotokology. 7 (5): 48-51.

[4] Chen Qian. (2016). Retrospective study on the effect of induced abortion on women's mental health. Modern Practical Medicine. 28 (2): 237-238.

[5] Symptoms of Post-Abortion Syndrome. Post Abortion Syndrome. Retrieved on April 12, 2019 from http://www.prolife.com/ABORT12.html 
[6] Cao Yu. (2018). Abortion, infant abandonment trauma and sacrifice from the perspective of Chinese culture -- two clinical cases are taken as examples. In (Chair), Psychology: Connecting Science to Solutions. The 29th International Congress of Applied Psychology, Montréal, Canada.

[7] State Statistics Bureau. (2018). China Health Statistics Yearbook (2018). Beijing, China: China Academic Journal Electronic Publishing House.

[8] Cao Yu. (2015). An analysis of the "Sacrifice" Archetype from the perspective of Chinese Culture, Ph.D. Dissertation. Macau: City University of Macau.

[9] Zhu Jianjun. (2015). Anxious Chinese. Beijng: Beijing Normal University Publishing Group.

[10] Zhu Jianjun. (2004). Spiritual rings: psychological analysis and redemption of Chinese culture. Lanzhou: Dunhuang Literature and Art Publishing House.
[11] Jung. (2011). Symbol of life. Beijing: International Cultural Publishing Company.

[12] Jung. (2011). Prototype and Collective Unconsciousness (Translated by $\mathrm{Xu}$ Delin). Beijing: International Culture Publishing Company.

[13] Jung. (2017). The Development of Personality (Translated by Hu Qingying). Beijing: Zhonghua Book Company.

[14] Yuan Yuan \& Zhang Zhiqiang. (2014). Be a Warm Parent. Beijing: Beijing Normal University Publishing Group.

[15] Yuan Yuan. (2018). Imagery Communication Clinical Practice Guide (Second Edition). Beijing: Beijing Normal University Publishing Group.

[16] Yuan Yuan. Cao Yu \& Zhu Jianjun. (2018). Summary of Imagery Communication Clinical Techniques (Second Edition). Beijing: Beijing Normal University Publishing Group. 